\title{
Phenomenological Modeling of Formic Acid Fractionation of Sugarcane Bagasse by Integration of Operation Parameters as an Extended Combined Severity Factor
}

\author{
Xiaogang Chang ${ }^{1,2,3}$, Jingzhi Zhang ${ }^{2,3}$, Ruchun $\mathrm{Wu}^{1, *}$ and Xuebing Zhao ${ }^{2,3, * \mathbb{D}}$ \\ 1 Guangxi Key Laboratory of Chemistry and Engineering of Forest Products, School of Chemistry and \\ Chemical Engineering, Guangxi University for Nationalities, Nanning 530006, China; changxg18@163.com \\ 2 Key Laboratory of Industrial Biocatalysis, Ministry of Education; Tsinghua University, Beijing 100084, China; \\ zjz5599@163.com \\ 3 Institute of Applied Chemistry, Department of Chemical Engineering, Tsinghua University, \\ Beijing 100804, China \\ * Correspondence: wuruchun@gxun.edu.cn (R.W.); zhaoxb@mail.tsinghua.edu.cn (X.Z.)
}

check for updates

Citation: Chang, X.; Zhang, J.; Wu, R.; Zhao, X. Phenomenological Modeling of Formic Acid Fractionation of Sugarcane Bagasse by Integration of Operation Parameters as an Extended Combined Severity Factor. Molecules 2021, 26, 2753. https://doi.org/ $10.3390 /$ molecules 26092753

Academic Editor: Alicia Prieto

Received: 25 March 2021

Accepted: 5 May 2021

Published: 7 May 2021

Publisher's Note: MDPI stays neutral with regard to jurisdictional claims in published maps and institutional affiliations.

Copyright: (c) 2021 by the authors. Licensee MDPI, Basel, Switzerland. This article is an open access article distributed under the terms and conditions of the Creative Commons Attribution (CC BY) license (https:/ / creativecommons.org/licenses/by/ $4.0 /)$.

\begin{abstract}
In order to more conveniently simulate and optimize the solubilization of sugarcane bagasse components during formic acid (FA) fractionation, an extended combined severity factor (CSF ext) was defined to integrate various operation parameters as a single factor. Two phenomenological models based on Arrhenius and Logistic equations were further used to describe the phenomenological kinetics. Different data-processing methods were compared to fit the severity parameters and model constants. Both Arrhenius-based and Logistic-based models show satisfying fitting results, though the values of Arrhenius-based $C S F_{\text {ext }}\left(\mathrm{A}-C S F_{\text {ext }}\right)$ and Logistic-based $C S F_{\text {ext }}\left(\mathrm{L}-C S F_{\text {ext }}\right)$ were somewhat different under the same fractionation condition. The solubilization of biomass components increased with $C S F_{\text {ext }}$, but two distinct stages could be observed with inflection points at A-CSF ext of 42 or L-CSF ext of 43, corresponding to bulk and residual solubilization stages, respectively. For the enzymatic hydrolysis of cellulosic solids, the highest initial enzymatic glucan conversion (EGC@6h) was obtained at A-CSF ext of 39-40 or A-CSF ext of 40-41; however, for a long hydrolysis period (72 h), relatively high glucan conversion (EGC@72h) was observed at A-CSF ext of 42-43 or A-CSF ext of 43-44. Post-treatment for deformylation with a small amount of lime could help to recover the cellulose digestibility.
\end{abstract}

Keywords: lignocellulosic biomass; formic acid fractionation; phenomenological modeling; extended combined severity factor

\section{Introduction}

Currently, in the face of multiple challenges such as oil shortage, climate change and environmental pollution, a reduction in the dependence on traditional fossil energy sources has aroused increasing attention. Therefore, the utilization of green and renewable resources to produce fuel is an important direction for low-carbon development [1]. Lignocellulosic biomass, with a huge yield and low price, has been considered as one of the most important renewable feedstocks for producing biofuels, such as ethanol, which has been commercially used as a substitute for fossil gasoline [2,3]. However, during the bioconversion of lignocellulose to bioethanol, pretreatment is a key step to improve the cellulose hydrolyzability for efficient release of sugars from the plant cell wall. This was mainly due to the biomass recalcitrance constructed by cell wall components, mainly hemicellulose and lignin, and their complicated interactions [4]. Therefore, removing hemicelluloses and lignin can greatly increase cellulose accessibility by exposing the cellulose surface [5]. Various pretreatment methods have been developed to overcome biomass recalcitrance, among which organosolv pretreatment can provide a unique way of achieving both the effective 
exposure of cellulose surface to increase its digestibility and fractionation of biomass to obtain cellulose-rich solids, hemicelluloses and high-purity lignin [6,7]. Formic acid (FA) has been considered as a good solvent for the fractionation of lignocellulosic biomass, because of its acidity and good ability to dissolve lignin [8]. Good fractionation of biomass components was achieved by FA treatment of various lignocellulose, such as sugarcane bagasse [9,10], wheat straw [11], corn stover [12] and even woody biomass [13]. However, flexible control of the operation parameters of the fractionation process based on kinetics is important in order to maximize the efficiency. Nevertheless, unfortunately, chemical pretreatment of biomass is a typical complex reaction system involving liquid-solid twophase or gas-liquid-solid three-phase reactions, while rigorous kinetic modeling based on a set of elementary steps is not possible. Therefore, modeling such complex systems is essentially phenomenological. Thus, the estimated kinetic parameters are functions of the ranges of experimental conditions used [14]. For example, a severity factor (SF, also termed a severity ordinate, shown as Equation (1) was introduced to integrate the effects of several factors on an evaluation of the biomass pretreatment process, especially for dilute acid prehydrolysis [14,15]. SF is also more convenient in industrial applications for such complex reactions because it combines the effects of the different operational variables into a single parameter

$$
S F=\log R_{0}=\log \left[t \times \exp \left(\frac{T-T_{\text {ref }}}{14.75}\right)\right]
$$

where $R_{C 0}$ is the severity parameter; $t$ is pretreatment time (min); $T$ is pretreatment temperature $\left({ }^{\circ} \mathrm{C}\right)$; and $T_{\text {ref }}$ is reference temperature and usually selected as $100{ }^{\circ} \mathrm{C}$. However, in $S F$, the contribution of acidity is not considered. To include the effect of acidity on pretreatment severity, a combined severity factor (CSF) was further defined, as shown in Equation (2) [16]

$$
C S F=\log R_{C 0}=\log \left[t \times \exp \left(\frac{T-T_{\text {ref }}}{14.75}\right)-\mathrm{pH}\right]
$$

where $R_{C 0}$ is the combined severity parameter. CSF has been widely and directly used to investigate the reaction conditions for different pretreatments or fractionations of various biomass feedstocks, including dilute acid pre-hydrolysis [17,18], steam explosion $[19,20]$ and organosolv processes [21,22]. However, for organosolv fractionation process, the solvent's contribution to severity should be also considered. As was found by Zhao and Liu [23], during the acid-catalyzed acetic acid delignification of sugarcane bagasse, the acetic acid concentration affected the solubility parameter of the solution and the ability to form hydrogen bonds with lignin fragments, which significantly affected the observed kinetic behavior of delignification. To further involve the contribution of solvent to the organosolv pretreatment of lignocellulosic biomass, our group defined an extended combined severity factor ( $C S F_{\text {ext }}$ ) (Equation (3)) for the phenomenological modeling of FA fractionating pretreatment of wheat straw, and the model parameters were fitted by experimental data of xylan and lignin solubilization [24]. The developed model showed a satisfying prediction of xylan solubilization as well as delignification under different conditions.

$$
C S F_{\mathrm{ext}}=\left(\frac{T-T_{f}}{\omega}\right)+\ln t+m \ln C_{\mathrm{sol}}+n \ln C_{\mathrm{cat}}
$$

$C S F_{\text {ext }}$ may provide a more general definition of the severity factor and can be applied as an integrated parameter, involving the contribution of temperature, time, solvent and catalyst concentrations, for evaluating the pretreatment process. Therefore, the objective of this work is to study whether the CSF ext can be applied for the phenomenological modeling of the FA fractionation of another biomass feedstock, sugarcane bagasse. Notably, how to fit the model parameters based on experimental data was further investigated. The finding of this work may provide useful information to guide the phenomenological modeling of the biomass pretreatment process by integrating the contribution of different factors as a single factor to optimize the operation parameters. 


\section{Results}

\subsection{Definition of Extended Combined Severity Factor and Phenomenological Modeling}

In the definition of $C S F_{\text {ext }}$ (Equation (3)), the total reaction severity is calculated by sum of the "contribution" of each operation factor. Corresponding constants are involved, which reflect the relative significance of each factor. The lowest temperature used in the experiments is usually selected as the $T_{\text {ref }}$. For example, for dilute acid pretreatment, $T_{\text {ref }}$ is usually selected as $100{ }^{\circ} \mathrm{C}$, as initially defined by Chum et al. [16], while, for FA fractionating pretreatment of wheat straw, $70{ }^{\circ} \mathrm{C}$ was selected as the $T_{\text {ref }}$ [24]. $\omega$ is an experiment-determined severity parameter related to the reduced activation energy [16]; $t$ is reaction time with a unit of minute; $C_{\mathrm{sol}}$ and $C_{\mathrm{cat}}$ are solvent and catalyst concentrations with units of $\mathrm{mol} / \mathrm{L}$, respectively; $m$ and $n$ are the observed reaction orders with respect to solvent and catalyst concentrations, respectively. In the present work, no external mineral acid catalyst was used, because FA played the role of both catalyst (since FA can dissociate $\mathrm{H}^{+}$) and lignin solvent; therefore, the contribution of catalyst $\left(\mathrm{H}^{+}\right)$can be incorporated into the effect of solvent concentration. Thus, the corresponding extended combined severity factor $\left(C S F_{\text {ext }}\right)$ for FA pretreatment of sugarcane bagasse in this work can be simplified as

$$
C S F_{\text {ext }}=\left(\frac{T-T_{f}}{\omega}\right)+m \ln C_{\mathrm{FA}}+\ln t
$$

where $C_{\mathrm{FA}}$ is FA concentration in mol/L. The determination of the constants $\omega$ and $m$ is thus the first step in the phenomenological modeling of FA fractionation of sugarcane bagasse. However, different results may be obtained when experimental data on the solubilization of different polymeric components of biomass are used for fitting, because these components showed different $\omega$ and $m$ reaction behaviors in response to the reaction conditions. For instance, in dilute acid hydrolysis, xylan is the primary component removed, and thus it is better to use the experimental data of xlyan removal (or xylose yield) to determine $\omega$ [24]. In the FA fractionation process, both xylan and lignin are significantly removed, and, thus, data on xylan and lignin solubilization should be used to determine the constants. A comparison of the different data-processing methods used to fit these constants was the major objective of this work.

For phenomenological modeling with $C S F_{\text {ext }}$, at least two models have been proposed, as reported by Dong et al. [24], namely, models based on the Arrhenius equation and modified Logistic equation. The Arrhenius equation-based model assumes that the solubilization of biomass components follows a typical homogeneous first-order mechanism, while the Logistic equation-based model employs the assumption that the rate of the biomass component solubilization is a first-order reaction with respect to the degree of solubilization itself, as well as the un-removed fraction. By defining the main objective function, the degree of polymeric component solubilization $(\alpha)$ as the weight ratio of solubilized fraction to the initial part of the component, the model based on Arrhenius equation assumes that $\ln [-\ln (1-\alpha)]$ has a phenomenologically linear relationship with $C S F_{\text {ext }}$, namely

$$
\alpha=1-\exp \left[-\exp \left(a C S F_{\text {ext }}+b\right)\right]
$$

where $a$ and $b$ are model parameters. The model based on the modified Logistic equation assumes that $\ln (1 /(1-\alpha)-1)$ has a linear relationship with $C S F_{\text {ext }}$, namely

$$
\alpha=1-\frac{1}{1+\exp \left(q C S F_{\text {ext }}+c\right)}
$$

where $q$ and $c$ are corresponding model parameters. Therefore, the severity constants $\omega$ and $m$ in $C S F_{\text {ext }}$, and the linear relationship parameters $a$ and $b, q$ and $c$ can be determined by a multiple linear regression of experimental data at different pretreatment temperatures, times and FA concentration levels. 


\subsection{Determination of Severity Constants and Model Parameters}

During FA pretreatment, a significant removal of xylan and lignin was observed. A portion of cellulose can also be solubilized. Therefore, the severity constants should mainly be determined by the experimental data of xylan and lignin solubilization under different pretreatment conditions. However, even so, there are still different methods for data processing. For example, the severity constants, $\omega$ and $m$, can be separately fitted by experimental data of xylan and lignin solubilization, and averages were then used as the final determined values, as performed by Dong et al. [24]. When the fitted values of $\omega$ and $m$ were similar for xylan solubilization and delignification, this data-processing method make sense. However, if the fitted values are much different, using the average as the final value may lead to large errors. Therefore, more data-processing methods should be further studied and compared. In this work, the severity constants and model parameters were separately fitted with experimental data on solubilization of xylan, lignin, xylan plus lignin fraction, and total biomass, as shown in Table 1. Corresponding plots of experimental data and model-predicted data for xylan and lignin solubilization with respect to CSF ext are shown in Figures 1 and 2.

Table 1. Determination of severity constants and model parameters by multiple linear regressions of experimental data under different conditions with different data-processing methods.

\begin{tabular}{|c|c|c|c|c|c|c|c|c|}
\hline \multirow{6}{*}{$\begin{array}{l}\text { Model based on } \\
\text { Arrhenius } \\
\text { equation }\end{array}$} & \multirow{2}{*}{ Data Used for Fitting } & \multicolumn{7}{|c|}{ Fitted Severity Parameters and Kinetic Constants } \\
\hline & & $\omega$ & $m$ & $a$ & $b$ & $R^{2}$ & $F$ Value & $p$ Value \\
\hline & Xylan solubilization & 22.53 & 8.23 & 0.1632 & -4.30 & 0.8337 & 127.02 & 0 \\
\hline & Lignin solubilization & 11.06 & 16.10 & 0.1439 & -7.41 & 0.9076 & 295.74 & 0 \\
\hline & $\begin{array}{l}\text { Xyan plus lignin } \\
\text { solubilizaiton }\end{array}$ & 0.1446 & 12.10 & 14.54 & -5.5595 & 0.9142 & 269.84 & 0 \\
\hline & $\begin{array}{l}\text { Total biomass } \\
\text { solubilization }\end{array}$ & 0.1193 & 8.9665 & 78.4760 & -4.1200 & 0.5960 & 37.38 & 0 \\
\hline \multirow{5}{*}{$\begin{array}{l}\text { Model based on } \\
\text { Logistic equation }\end{array}$} & Data Used for Fitting & $\omega$ & $m$ & $q$ & $c$ & $R^{2}$ & $F$ Value & $p$ Value \\
\hline & Xylan solubilization & 22.24 & 8.51 & 0.3093 & -7.88 & 0.8496 & 143.06 & 0 \\
\hline & Lignin solubilization & 10.40 & 16.83 & 0.2459 & -12.60 & 0.9152 & 143.06 & 0 \\
\hline & $\begin{array}{l}\text { Xyan plus lignin } \\
\text { solubilizaiton }\end{array}$ & 0.2640 & 12.52 & 13.91 & -9.9289 & 0.9210 & 295.26 & 0 \\
\hline & $\begin{array}{l}\text { Total biomass } \\
\text { solubilization }\end{array}$ & 0.1536 & 9.1787 & 87.6569 & -4.9242 & 0.6003 & 38.05 & 0 \\
\hline
\end{tabular}

The results illustrate that both models showed a good degree of fitting to the experiment-determined data with high determination coefficients $\left(R^{2}>0.83\right)$ for xylan solubilization, delignification $\left(R^{2}>0.91\right)$ and xylan plus lignin solubilization $\left(R^{2}>0.91\right)$. The deviation between predicted data and experimental data was generally in the range of \pm 10 -However, for total biomass solubilization, $R^{2}$ was only about 0.60 and the deviation was $20 \%$. This was because the kinetics of solubilization of xylan and hemicellulose during FA fractionation were similar, but the solubilization of glucan showed very different kinetic behavior; thus, a high deviation could be observed when the data of total biomass solubilization were used for fitting. Nevertheless, the $F$ values for each data-processing method were very high, with correspondingly very low $P$ values, indicating that these models (Equation (5) and Equation (6)) were statistically significant in describing the phenomenological kinetics of solubilization of the biomass component during FA pretreatment. Both Logistic equation-based and Arrhenius based models showed a very similar degree of fitting. Table 1 also shows that the value of $\omega$ was not a fixed constant and varied depending on the data-processing methods. The value of $m$ was high, indicating that FA concentration had a very significant effect on the fractionation, and thus made a significant contribution to $C S F_{\text {ext }}$. Figure 1 and Table 1 also suggested that the data of xylan plus lignin solubilization, namely by considering the xylan and lignin as a soluble fraction of 
biomass, were preferred to fit the model parameters. Thus, the $C S F_{\text {ext }}$ for FA fractionation of sugarcane bagasse can be calculated according to pretreatment conditions as follows.
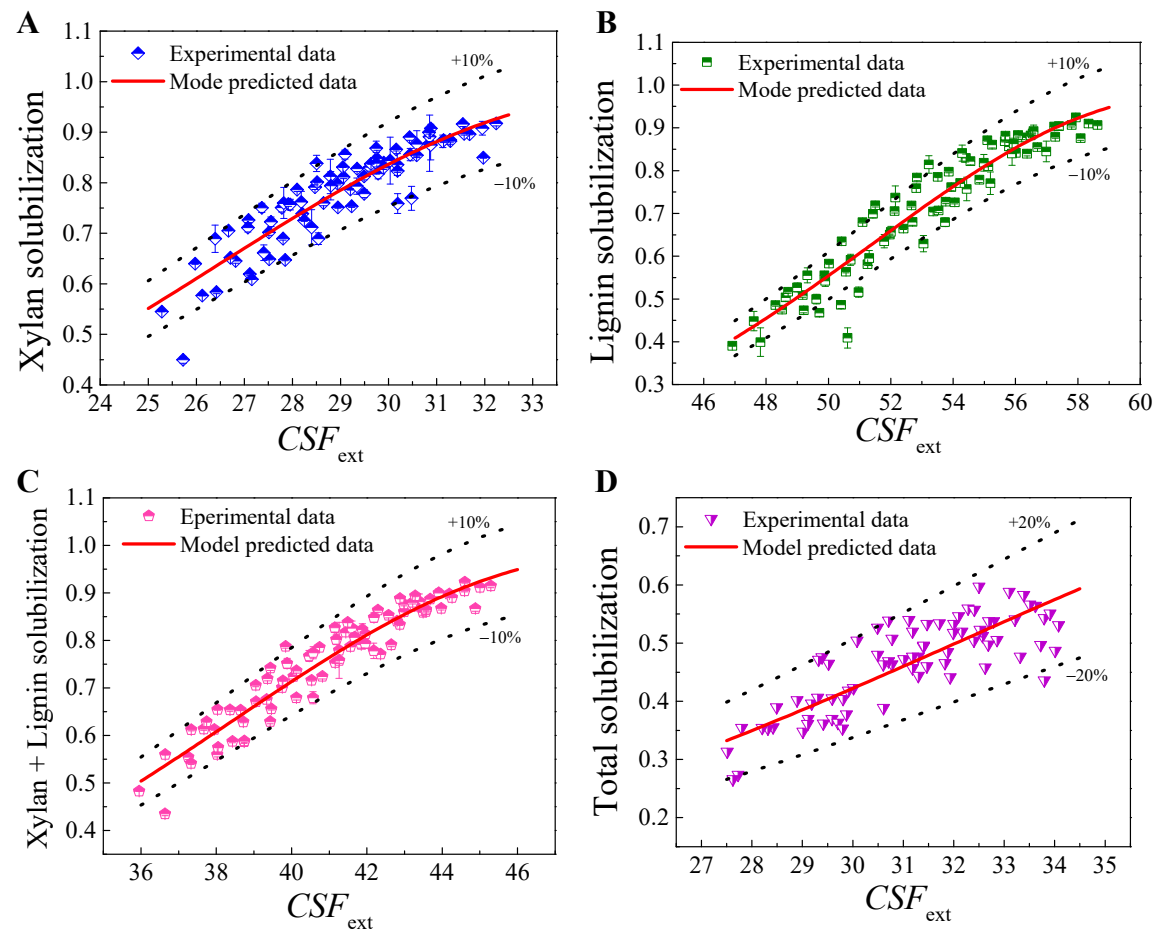

Figure 1. Fitting of severity constants and model parameters with Arrhenius equation-based model. (A) with xylan solubilization data for fitting; (B) with lignin solubilization data for fitting; (C) with xylan plus lignin solubilization data for fitting; and (D) with total biomass solubilization data for fitting.
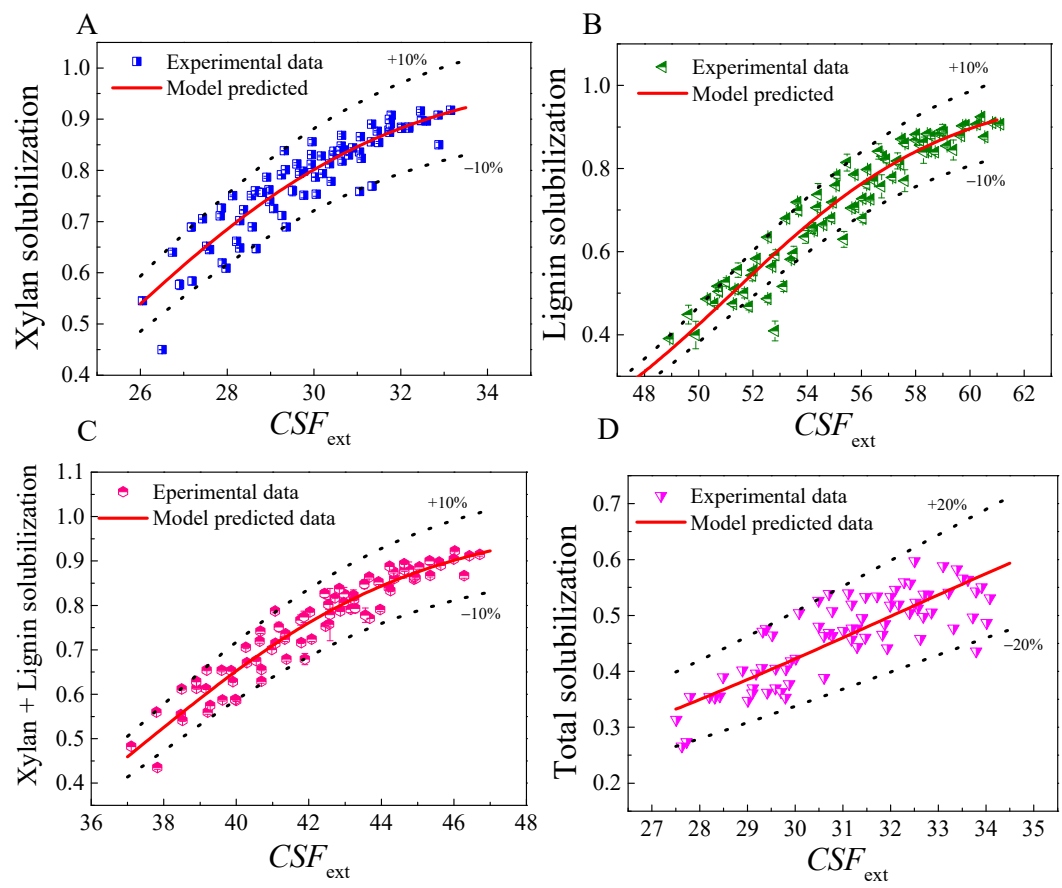

Figure 2. Fitting of severity constants and model parameters with Logistic equation-based model. (A) with xylan solubilization data for fitting; (B) with lignin solubilization data for fitting; (C) with xylan plus lignin solubilization data for fitting; (D) with total biomass solubilization data for fitting. 
Based on Arrhenius equation (A-CSF $\left.F_{\text {ext }}\right)$

$$
\mathrm{A}-C S F_{\mathrm{ext}}=\left(\frac{T-70}{16.795}\right)+12.165 \ln C_{\mathrm{FA}}+\ln t
$$

Based on Logistic equation (L-CSF $\left.F_{\text {ext }}\right)$

$$
\mathrm{L}-C S F_{\text {ext }}=\left(\frac{T-70}{16.32}\right)+12.67 \ln C_{\mathrm{FA}}+\ln t
$$

\subsection{Application of the Extended Severity Factor to Evaluate the Pretreatment Process}

2.3.1. Use of $C S F_{\text {ext }}$ as an Integrated Parameter to Correlate Operation Condition with Solubilization of Biomass Components

Plots of the total biomass, glucan, xylan and lignin solubilizations versus Arrheniusbased (Equation (7)) $C S F_{\text {ext }}$ and Logistic-based $C S F_{\text {ext }}$ (Equation (8)) are shown in Figures 3 and 4, respectively. A very similar tendency was observed for both plots of biomass component solubilization with Arrhenius-based and Logistic-based CSF ext. As shown in Figures $3 \mathrm{~A}$ and $4 \mathrm{~A}$, xylan solubilization increased significantly in the range

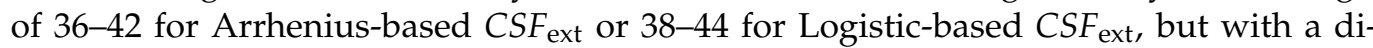
minishing rate at a $C S F_{\text {ext }}$ higher than 42 (Arrhenius-based) or 44 (Logistic-based). For delignification, lignin solubilization changed in the range of 0.4-1.0, when $C S F_{\text {ext }}$ increased from 36 to 48 . However, inflection points can be observed at an Arrhenius-based CSF ext of 43 or Logistic-based $C S F_{\text {ext }}$ of 44 . This was mainly because the residual lignin was difficult to remove even though the reaction severity was further enhanced, which could also be explained by the marginal effect. For glucan solubilization, the datapoints were very discrete, but an implicit tendency could be observed, where glucan solubilization slightly increased and then decreased. The highest glucan solubilization seemed to appear at a $C S F_{\text {ext }}$ of 40-43. Higher $C S F_{\text {ext }}$ seemed to oppositely decrease glucan solubilization. This was probably because the high concentration of FA could significantly contribute to the $C S F_{\text {ext }}$ but less water was present in the system, thus reducing the hydrolysis of cellulose. However, the glucan solubilization was relatively small, and larger errors could occur in the experiments. For total biomass solubilization, a similar tendency to that of xylan solubilization was found. A relatively rapid increase in total biomass solubilization was observed at an Arrhenius-based CSF ext of 36-42 or Logistic-based $C S F_{\text {ext }}$ of 38-44. This was primarily due to the solubilization of xylan and lignin. A further increase in $C S F_{\text {ext }}$ just slightly increased the total biomass solubilization, which was mainly due to the difficulties in the solubilization of cellulose and residual xylan and lignin. However, the objective of FA fractionation is to liberate cellulose fiber from the cell wall matrix by removing hemicelluloses and lignin, and cellulose should be recovered as a solid phase. Thus the reaction was best performed at an Arrhenius-based $C S F_{\text {ext }}$ higher than 42 or Logistic-based $\mathrm{CSF}_{\text {ext }}$ higher than 43, particularly with a high FA concentration, for example, $90 \%$ FA.

\subsubsection{Evaluation of Enzymatic Digestibility of Cellulosic Solids}

The obtained cellulosic solid may have many applications. One of its uses is to produce glucose by enzymatic hydrolysis for the further production of biofuels such as ethanol. Therefore, experiments were further performed to investigate the effects FA fractionation condition on cellulose digestibility. An orthogonal experimental design $\left(\mathrm{L}_{16}\left(3^{5}\right)\right)$ was used to arrange the experimental runs with solid yield (SY), glucan content (GC), xylan content $(\mathrm{XC})$, lignin content (LC), xylan removal (XR), degree of delignification (DD), formyl group content (FC), enzymatic glucan conversion (EGC) at $6 \mathrm{~h}$ and $72 \mathrm{~h}$ as the objective variables. Corresponding $\mathrm{CSF}_{\text {ext }}$ were also calculated according to the operation parameters. The results are listed in Table 2. The CSF ext was in a wide range of 35-46, and the SY, XR and DD were in the range of $45-90 \%$, covering the typical results of FA fractionation. Because cellulose contains three hydroxyl groups in each glucose unit, formylation can take place during FA fractionation, leading to an increase in FC, which may reduce the molecular recognition of cellulases for hydrolysis [25]. Plots of $C S F_{\text {ext }}$ with FC of cellulosic solids 
are shown in Figure 5A,B. It is clear that FC continuously increased with $C S F_{\text {ext }}$, but FC was just slightly increased with $C S F_{\text {ext }}$ at A-CSF ext range of 36-41 or L-CSF ext range of 37-42. However, a significant increase in FC was observed at an A-CSF $F_{\text {ext }}$ higher than 41 or an L-CSF ext higher than 42 . This was primarily because, at this inflection point, a large portion of hemicelluloses and lignin was removed, leading to a significant exposure of cellulose, resulting in an increased degree of formylation. For enzymatic hydrolysis of cellulosic solid, EGC@6h and EGC@72h were compared, which represents the initial rate of enzymatic hydrolysis and final degree of enzymatic hydrolysis of glucan, respectively. Plots of EGC@6h and EGC@72h with A-CSF ext and L-CSF $F_{\text {ext }}$ are shown in Figure 4. It was observed that EGC@6h generally increased with A-CSF ext and L-CSF ext to achieve the maximal at the A-CSF ext of 39-40 or A-CSF ext of 40-41 (Figure 5C,D). Further increasing $C S F_{\text {ext }}$ oppositely reduced EGC@6h. This was because, at a low $C S F_{\text {ext }}$, the removal of hemicelluloses and lignin was not high enough, and thus the exposure of cellulose was not

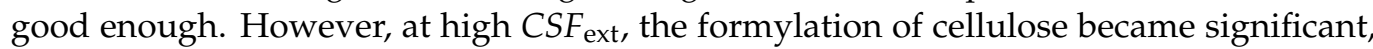
thus reducing the productive adsorption of cellulases for initiating the hydrolysis process. Nevertheless, EGC@72h seemed to be continually increasing with $C S F_{\text {ext }}$, but no further apparent increase was observed at an A-CSF ext higher than 41 or L-CSF ext higher than 42(Figure 5E,F). This phenomenon was highly in accordance with that observed for FC. The substitution of cellulose hydroxyl group by the formyl group may lead to interference for the recognition of cellulase enzymes to cellulose substrates by inhibiting the formation of hydrogen bonds (productive binding) between cellulose and the catalytic domain of cellulases [25]. The diameter of a cellulose chain might also be enlarged by formyl group substitution, which may reduce its chance entering the tunnel or groove in the catalytic domain of cellobiohydrolase, the most important cellulase component [26].
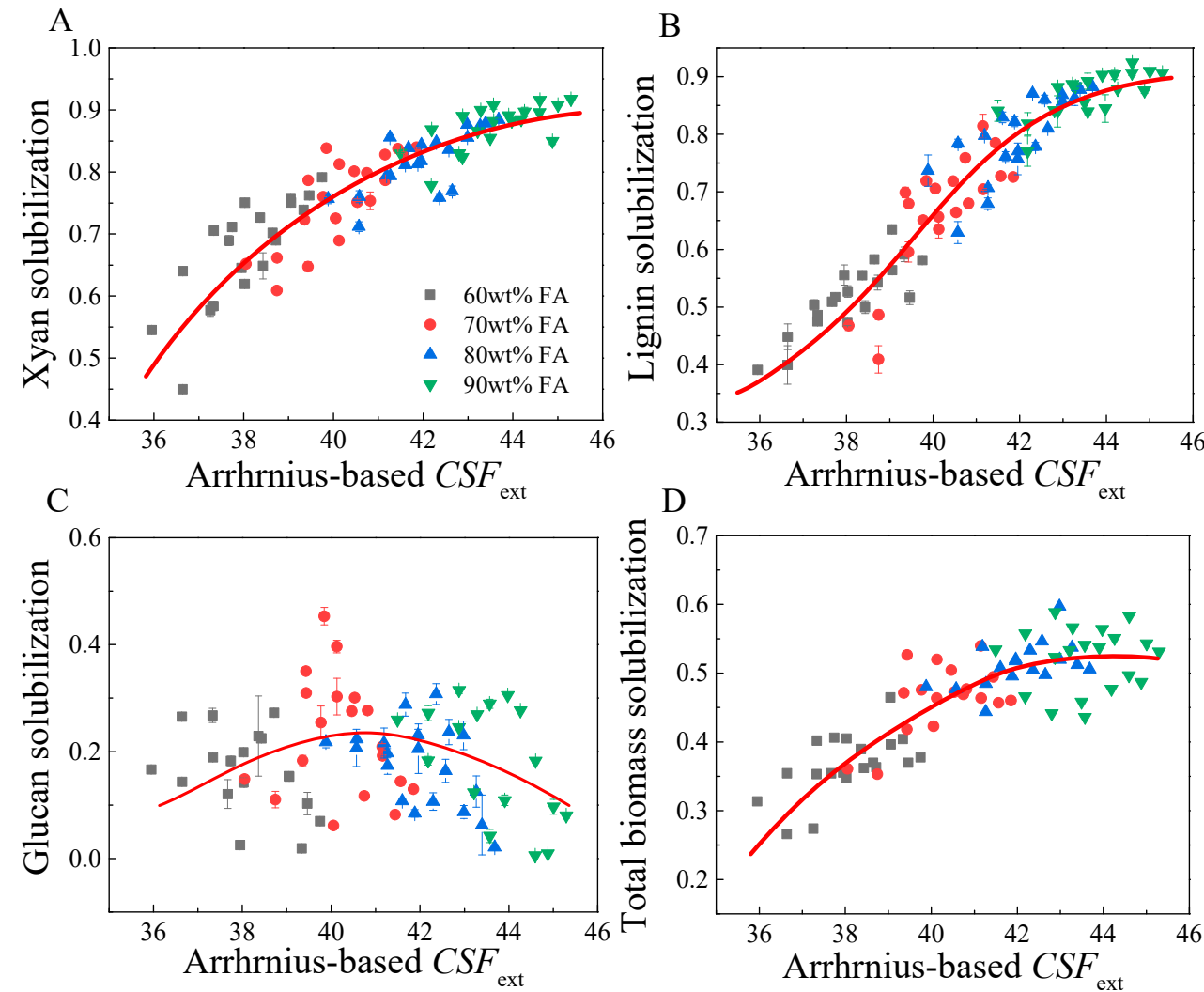

Figure 3. Plots of Arrhenius-based CSF ext with total xylan solubilization (A), lignin solubilization (B), glucan solubilization (C) and total biomass solubilization (D). 
A
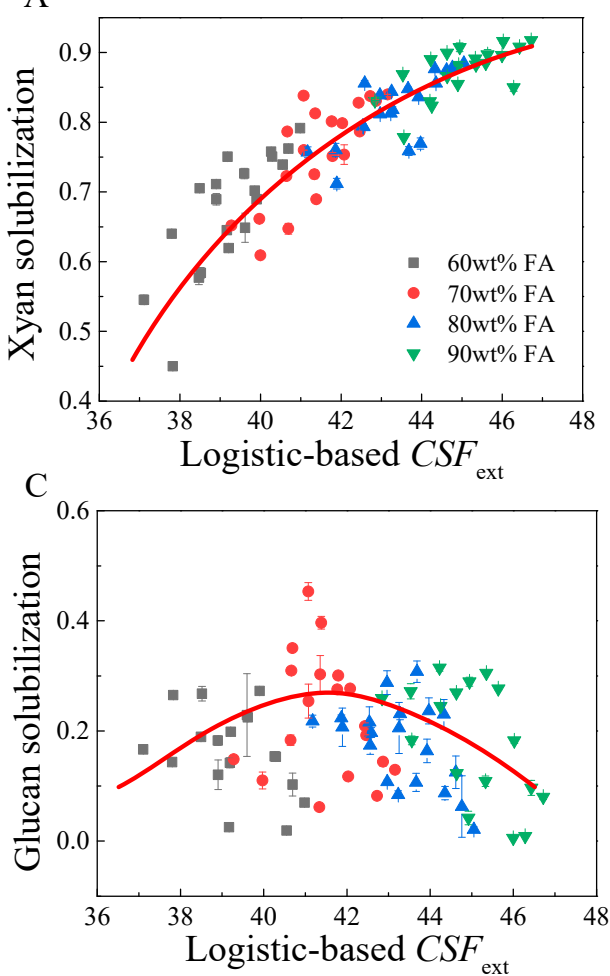

B

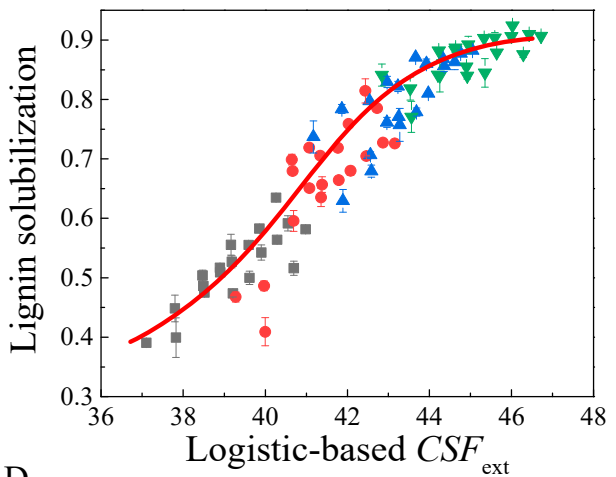

$\mathrm{D}$

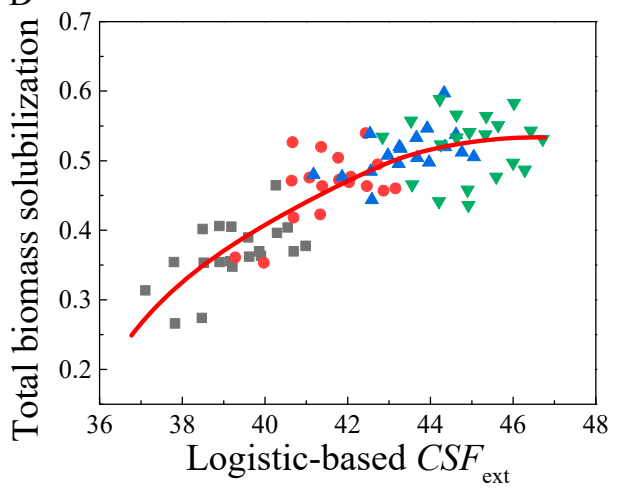

Figure 4. Plots of Logistic-based CSF ext with total xylan solubilization (A), lignin solubilization (B), glucan solubilization (C) and total biomass solubilization (D).

The results shown in Table 2 and Figure 5 thus suggested that the EGC of cellulosic solid obtained by FA fractionation was affected by operation condition, namely $C_{\text {, }} F_{\text {ext }}$, by a complicated mechanism. Increasing $C S F_{\text {ext }}$ resulted in a higher degree of removal of hemicelluloses and lignin, which were beneficial to expose cellulose surface for enzymatic hydrolysis. Notably, delignification has been found to greatly increase cellulose accessibility [27]. FA fractionation works like a chemical pulping process that liberates cellulose fibers by delignification. Once DD reaches a certain point, which is known as the point of fiber liberation or defibration point, the cellulose fiber becomes liberated, with little or no mechanical action [28]. After cellulose fiber is liberated, its accessibility is greatly improved [29].Therefore, a generally higher EGC can be obtained at a higher DD. However, because the formylation reaction became significant once cellulose fibers were liberated, the EGC of formylated cellulose was reduced. Therefore, apparently, the highest EGC was not obtained at the points with the highest degree of delignification. For example, the experimental results shown in Table 2 demonstrated that the highest DD $(89.2 \pm 1.4 \%)$ was obtained by Run \#8 at A-CSF ext $_{\text {of } 43.97 \text { or L-CSF }}$ ext of 45.35, but EGC@6h and EGC@72h were just $3.9 \pm 0.3 \%$ and $42.3 \pm 2.9 \%$, respectively. Thus, the above results indicated that, in order to recover the cellulose digestibility, deformylation was necessary.

In a practical process, an efficient way of eliminating the negative effects of the formyl group is alkaline saponification. For example, lime or ammonia can be used to remove the introduced formyl group. When ammonia is used, the formed ammonia salts can be utilized by yeast as a nitrogen source in the subsequent fermentation process. However, lime is usually much cheaper than ammonia. In the present work, the cellulosic solid obtained by FA fractionation performed at A-CSF ext of $\sim 43$ or L-CSF $F_{\text {ext }}$ of $\sim 44\left(80 \% \mathrm{FA}, 105^{\circ} \mathrm{C}, 0.5 \mathrm{~h}\right.$, as run \# 15 in Table 2 and $90 \%$ FA, $105^{\circ} \mathrm{C}, 0.25 \mathrm{~h}$ as run \# 16 Table 2) were further post-treated with $4 \mathrm{wt} \%$ lime based on the initial dry sugarcane bagasse solid. The chemical components and EGC of de-formylated solids are shown in Table 3. Most of the formyl groups could be removed, with the FC being reduced to less than $0.5 \%$. Compared with the samples without deformylation, the efficiency of long-time enzymatic digestion (EGC@72h) was 
significantly enhanced to 72-75\%, while the initial rate of enzymatic hydrolysis (EGC@6h) were even more significantly increased, from less than $6 \%$ of formylated substrates to higher than $40 \%$ of deformylated samples (Table 3), indicating the efficiency of deformylation for recovering the cellulose digestibility of cellulosic solids obtained by FA fractionation. In the experiments, we even found that, for a shorter hydrolysis, for example, $3 \mathrm{~h}$, the EGC of deformylated substrates could be as high as $30-35 \%$. These results corroborated that removing the formyl group promotes the recognition of cellulose molecules, thus improving the productive adsorption of cellulase enzymes.

A
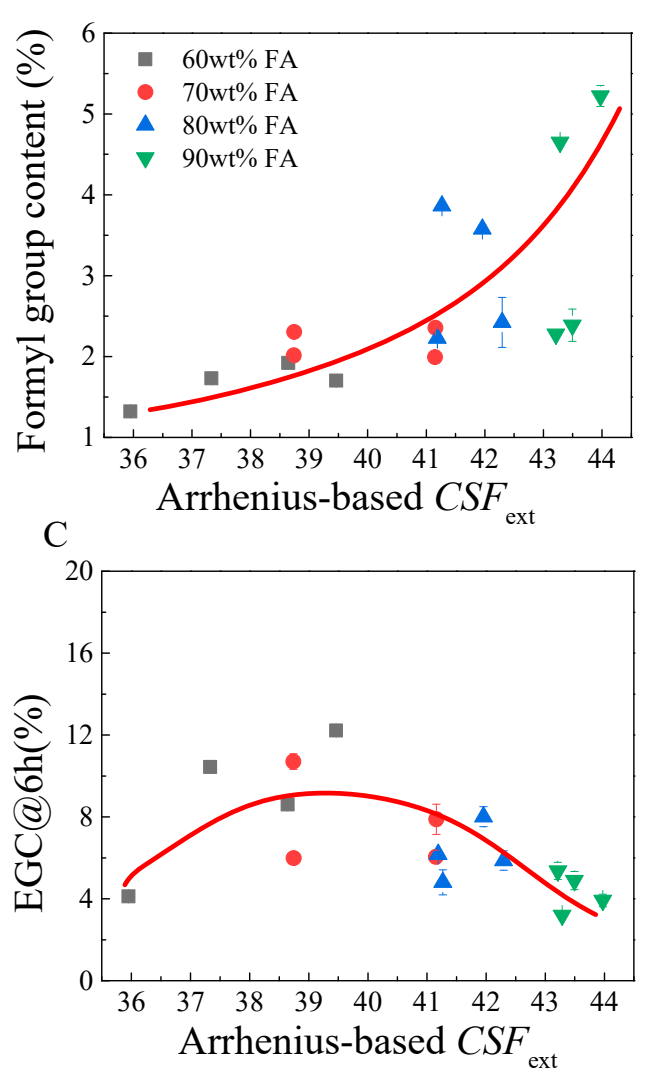

E

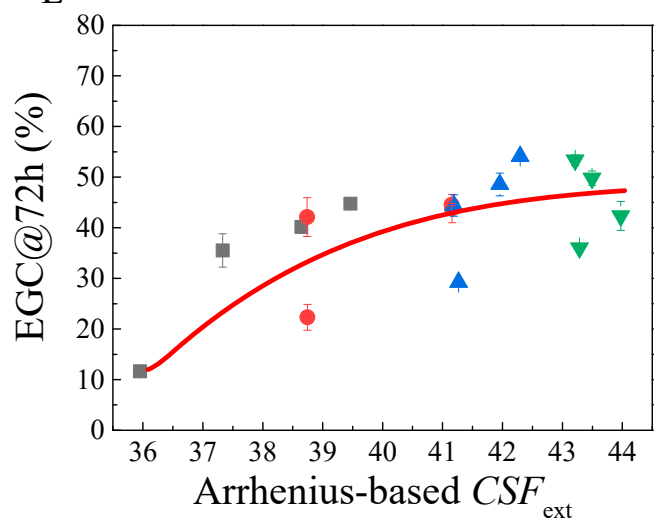

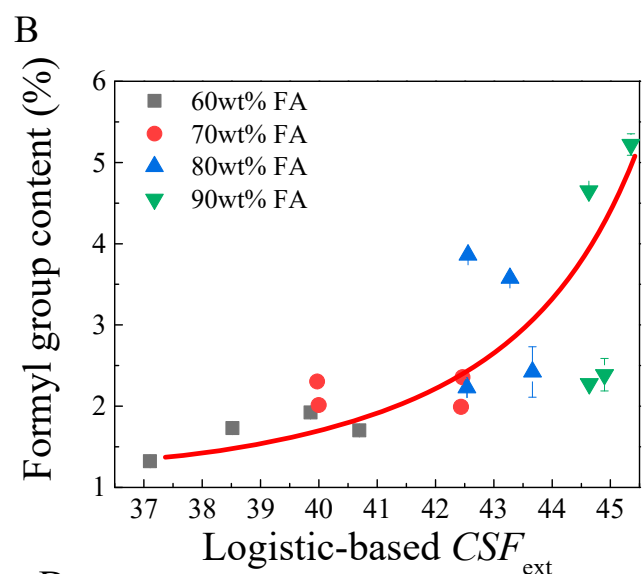

$\mathrm{D}$

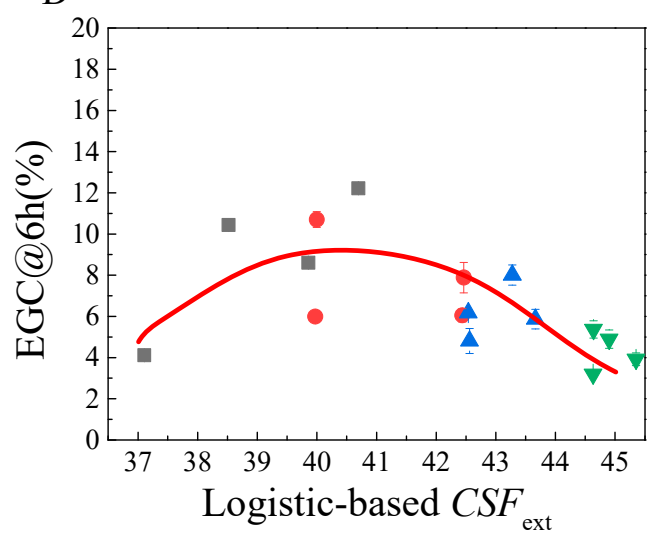

$\mathrm{F}$

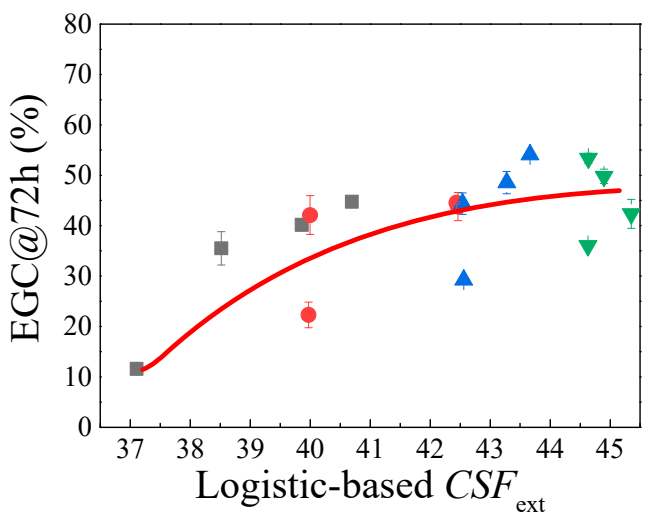

Figure 5. Plots of $C S F_{\text {ext }}$ with formyl group content $(\mathrm{FC})(\mathbf{A}, \mathbf{B})$ and enzymatic glucan conversion (C-F) of pretreated cellulosic solid. 
Table 2. Orthogonal experiments and results of enzymatic digestion of bagasse pretreated with formic acid.

\begin{tabular}{|c|c|c|c|c|c|c|c|c|c|c|c|c|c|c|}
\hline \multirow[b]{2}{*}{ No. } & \multirow[b]{2}{*}{$\begin{array}{c}T \\
\left({ }^{\circ} \mathrm{C}\right)\end{array}$} & \multirow[b]{2}{*}{$\begin{array}{l}C_{\mathrm{FA}} \\
(\%)\end{array}$} & \multirow[b]{2}{*}{$\begin{array}{c}t \\
\text { (h) }\end{array}$} & \multirow[b]{2}{*}{$\mathrm{A}-C S F_{\mathrm{ext}}$} & \multirow[b]{2}{*}{$\mathrm{L}-C S F_{\text {ext }}$} & \multicolumn{7}{|c|}{ Experimental Results } & \multirow[b]{2}{*}{$\begin{array}{c}\text { EGC } \\
@ 6 h \\
(\%)\end{array}$} & \multirow[b]{2}{*}{$\begin{array}{c}\text { EGC } \\
@ 72 \mathrm{~h} \\
(\%)\end{array}$} \\
\hline & & & & & & $\begin{array}{l}\text { SY } \\
(\%)\end{array}$ & $\begin{array}{l}\text { GC } \\
(\%)\end{array}$ & $\begin{array}{l}\text { XC } \\
(\%)\end{array}$ & $\begin{array}{c}\text { LC } \\
(\%)\end{array}$ & $\begin{array}{l}\text { XR } \\
(\%)\end{array}$ & $\begin{array}{l}\text { DD } \\
\text { (\%) }\end{array}$ & $\begin{array}{l}\text { FC } \\
(\%)\end{array}$ & & \\
\hline 1 & 80 & 60 & 0.25 & 35.95 & 37.11 & 68.7 & $56.17 \pm 0.19$ & $17.93 \pm 0.09$ & $21.16 \pm 0.05$ & $54.5 \pm 0.3$ & $39.06 \pm 0.09$ & $1.3 \pm 0.03$ & $4.1 \pm 0.1$ & $11.6 \pm 0.1$ \\
\hline 2 & 80 & 70 & 0.5 & 38.75 & 39.97 & 64.7 & $63.7 \pm 0.2$ & $14.2 \pm 0.2$ & $18.9 \pm 0.4$ & $66.2 \pm 0.5$ & $48.6 \pm 0.8$ & $2.3 \pm 0.01$ & $6.0 \pm 0.2$ & $22.3 \pm 2.5$ \\
\hline 3 & 80 & 80 & 1 & 41.27 & 42.56 & 51.6 & $74.2 \pm 0.8$ & $10.9 \pm 0.06$ & $13.6 \pm 0.3$ & $79.4 \pm 0.1$ & $70.7 \pm 0.5$ & $3.9 \pm 0.02$ & $4.8 \pm 0.6$ & $29.2 \pm 0.4$ \\
\hline 4 & 80 & 90 & 1.5 & 43.29 & 44.63 & 43.4 & $77.9 \pm 0.3$ & $6.3 \pm 0.05$ & $6.7 \pm 0.2$ & $89.9 \pm 0.1$ & $88.3 \pm 0.4$ & $4.7 \pm 0.04$ & $3.2 \pm 0.1$ & $36.0 \pm 0.2$ \\
\hline 5 & 90 & 60 & 0.5 & 37.33 & 38.52 & 64.7 & $52.4 \pm 1.2$ & $17.4 \pm 0.3$ & $19.4 \pm 0.02$ & $58.4 \pm 0.8$ & $47.5 \pm 0.1$ & $1.7 \pm 0.02$ & $10.4 \pm 0.2$ & $35.5 \pm 3.3$ \\
\hline 6 & 90 & 70 & 0.25 & 38.74 & 40.00 & 79.1 & $60.4 \pm 1.6$ & $13.4 \pm 0.02$ & $13.9 \pm 0.7$ & $60.9 \pm 0.1$ & $54.6 \pm 2.4$ & $2.1 \pm 0.05$ & $10.7 \pm 0.4$ & $42.1 \pm 3.8$ \\
\hline 7 & 90 & 80 & 1 & 41.96 & 43.28 & 49.6 & $64.6 \pm 1.8$ & $13.2 \pm 0.4$ & $10.7 \pm 0.3$ & $75.9 \pm 0.6$ & $77.9 \pm 0.7$ & $3.6 \pm 0.05$ & $8.0 \pm 0.5$ & $48.6 \pm 2.2$ \\
\hline 8 & 90 & 90 & 1.5 & 43.97 & 45.35 & 45.9 & $71.6 \pm 1.6$ & $9.9 \pm 0.01$ & $5.9 \pm 0.7$ & $90.8 \pm 0.01$ & $89.2 \pm 1.4$ & $5.2 \pm 0.1$ & $3.9 \pm 0.3$ & $42.3 \pm 2.9$ \\
\hline 9 & 99 & 60 & 1 & 38.64 & 39.86 & 63.0 & $69.4 \pm 0.1$ & $11.5 \pm 0.06$ & $17.3 \pm 0.1$ & $70.2 \pm 0.1$ & $58.3 \pm 0.2$ & $1.93 \pm 0.01$ & $8.6 \pm 0.2$ & $40.8 \pm 1.1$ \\
\hline 10 & 99 & 70 & 1.5 & 41.15 & 42.45 & 46.0 & $74.5 \pm 0.5$ & $9.1 \pm 0.09$ & $10.8 \pm 1.1$ & $82.8 \pm 0.2$ & $81.5 \pm 2.0$ & $2.0 \pm 0.02$ & $6.1 \pm 0.3$ & $44.6 \pm 0.2$ \\
\hline 11 & 99 & 80 & 0.25 & 41.19 & 42.54 & 46.1 & $73.7 \pm 0.05$ & $10.9 \pm 0.2$ & $11.8 \pm 0.1$ & $79.4 \pm 0.4$ & $79.8 \pm 0.3$ & $2.23 \pm 0.001$ & $6.2 \pm 0.1$ & $44.4 \pm 2.1$ \\
\hline 12 & 99 & 90 & 0.5 & 32.28 & 44.90 & 54.2 & $81.5 \pm 1.2$ & $6.5 \pm 0.1$ & $7.3 \pm 0.2$ & $85.5 \pm 0.2$ & $85.5 \pm 0.4$ & $2.39 \pm 0.2$ & $4.9 \pm 0.5$ & $49.8 \pm 1.4$ \\
\hline 13 & 105 & 60 & 1.5 & 39.46 & 40.70 & 63.0 & $65.9 \pm 1.5$ & $10.2 \pm 0.2$ & $18.0 \pm 0.4$ & $76.2 \pm 0.5$ & $51.6 \pm 1.2$ & $1.7 \pm 0.04$ & $12.2 \pm 0.2$ & $44.8 \pm 0.6$ \\
\hline 14 & 105 & 70 & 1 & 41.16 & 42.46 & 53.6 & $69.7 \pm 0.5$ & $10.8 \pm 0.02$ & $13.1 \pm 0.1$ & $78.7 \pm 0.04$ & $70.5 \pm 0.2$ & $2.4 \pm 0.02$ & $7.9 \pm 0.73$ & $43.8 \pm 6.8$ \\
\hline
\end{tabular}


Table 3. Analysis and enzymatic digestion of lime-deformylated solids.

\begin{tabular}{ccccccccc}
\hline & \multicolumn{7}{c}{ Experimental Results } \\
\cline { 2 - 8 } De-formylated Solid & $\begin{array}{c}\text { SY } \\
\mathbf{( \% )}\end{array}$ & $\begin{array}{c}\text { GC } \\
\mathbf{( \% )}\end{array}$ & $\begin{array}{c}\text { XC } \\
\mathbf{( \% )}\end{array}$ & $\begin{array}{c}\text { LC } \\
\mathbf{( \% )}\end{array}$ & $\begin{array}{c}\text { DD } \\
\mathbf{( \% )}\end{array}$ & $\begin{array}{c}\text { FC } \\
\mathbf{( \% )}\end{array}$ & $\begin{array}{c}\text { EGC@6h } \\
\mathbf{( \% )}\end{array}$ & $\begin{array}{c}\text { EGC@72h } \\
\mathbf{( \% )}\end{array}$ \\
\hline $\begin{array}{c}\text { Cellulosic solid obtained } \\
\text { with 80\% FA, } 105^{\circ} \mathrm{C}, \\
0.5 \mathrm{~h}\end{array}$ & 55.0 & $80.2 \pm 8.0$ & $9.7 \pm 0.9$ & $9.3 \pm 0.09$ & $78.8 \pm 0.2$ & $0.22 \pm 0.01$ & $43.7 \pm 1.6$ & $72.1 \pm 1.4$ \\
\hline $\begin{array}{c}\text { Cellulosic solid obtained } \\
\text { with 90\% FA, } 105^{\circ} \mathrm{C} \text {, } \\
0.25 \mathrm{~h}\end{array}$ & 53.1 & $82.7 \pm 4.5$ & $9.3 \pm 0.5$ & $8.0 \pm 0.1$ & $82.4 \pm 0.3$ & $0.39 \pm 0.03$ & $40.9 \pm 1.8$ & $74.9 \pm 0.3$ \\
\hline
\end{tabular}

Therefore, the above results indicated that $C S F_{\text {ext }}$ could be applied as an integrated parameter to evaluate the phenomenological kinetics of FA fractionation of sugarcane bagasse. Compared with traditional pseudo-homogenous kinetics, $C S F_{\text {ext-based phenomenological }}$ modeling is simpler, with acceptable accuracy, but even more applicable in a practical industrial process to guide the selection of pretreatment conditions.

\section{Discussion}

The fractionation of lignocellulosic biomass with organosolv solvents takes place in a complicated system, in which mass transfer including external and internal diffusion of solvents and catalysts, as well as solubilized biomass components, and reactions of polysaccharides and lignin are involved. For such a complicated system, rigorous kinetic modeling is impossible. However, phenomenological modeling is usually useful for optimizing the operation conditions. $C S F_{\text {ext }}$ is an integrated parameter, considering the contribution of different factors such as temperature, time and solvent (FA) concentration. Such an integration is reasonable, because, to achieve similar fractionation efficiency, the reaction can be performed at a higher temperature for a shorter time or lower temperature for a longer time. However, the "contribution" of each factor to the reaction severity is different, so that an adjustable constant is introduced, corresponding to each factor. Therefore, fitting of the constants in CSF ext was the prerequisite step for phenomenological modeling. The relationship between fractionation efficiency, for example, xylan solubilization or degree of delignification and $C S F_{\text {ext }}$ definitely affects the values of fitted constants. Mathematically, many equations can be used to fit the experimental data. Nevertheless, it is better for the relationship to be deduced from a classic kinetic model, such as the Arrhenius equation. In this work, the solubilization of biomass components was considered as a linear increase with $C S F_{\text {ext, }}$ which was also applied in previous works [16,24]. An Arrhenius-based model that can be developed from a first-order pseudo-homogenous kinetic model was used to correlate the relationship between different factors and xylan or lignin solubilization. Moreover, a phenomenological model developed based on modified Logistic equation [24] was also used for comparison. Both models showed similar accuracy to fit the experimental data. However, since xylan, lignin and cellulose show different solulibization behaviors in FA fractionation, the fitted constants are different when different data-processing methods are used for fitting. As indicated in Table 1, differently fitted severity parameters and kinetic constants indeed could be obtained when data on the solubilization of xylan, lignin, xylan plus lignin and total biomass were used. During FA fractionation, xylan and lignin were the major components solubilized from solid phase to liquid phase. Thus, by considering xylan plus lignin as a "pseudo-soluble" fraction, the fitted constants seemed to be the most suitable and compromised. The results indicated that such a phenomenological model could describe the effects of different factors on the objective functions, such as xylan or lignin solubilization, with satisfying accuracy. Therefore, the $C S F_{\text {ext }}$ can be used as a powerful tool for optimizing the fractionation conditions and making a decision on the selection of optimal operation parameters. 
FA fractionation generally produces three products for further processing, namely, cellulosic solid, hemicellulosic syrup and high-purity lignin. The hemicellulosic sugars obtained from sugarcane bagasse are primarily composed of pentose such as xylose, which can be converted to furfural under the catalysis of residual formic acid [7,30]. Moreover, after detoxification, pentose also can be converted to microbial lipid, a promising feedstock for biodiesel production [1]. High-purity lignin has relatively high added-value, but the down-stream products and market still need to be further developed. For cellulosic solids obtained by FA fractionation, since the cellulose contents were high, due to the removal of hemicelluloses and lignin, they can be used for the production of cellulose-derived materials. The cellulosic solid also can be hydrolyzed by cellulase enzymes to produce fermentable sugars. However, formylation takes place via the esterification of cellulose hydroxyl groups, which leads to a decrease in the cellulose digestibility. The degree of formylation is largely dependent on the reaction severity, especially formic acid concentration. Therefore, cellulose formylation should be considered for the selection of suitable $C S F_{\text {ext }}$ when FA fractionation aims to increase the cellulose digestibility. Deformylation with bases such as ammonia, lime, etc., is necessary in order to recover the enzymatic hydrolysability of pretreated cellulosic solids. However, further investigation should be carried out, with consideration of the whole process design, and optimization from the perspective of techno-economics.

\section{Materials and Methods}

\subsection{Lignocellulosic Biomass and Chemicals}

Sugarcane bagasse used in the experiments was obtained from the Guangxi Zhuang Autonomous Region in South China. It was air-dried and screened by sieves. The portion that could not pass through 40-mesh sieve was collected for FA fractionation. The main components of the bagasse were determined to be $43.4 \pm 1.0 \%$ glucan, $24.4 \pm 0.6 \%$ xylan, $1.2 \pm 0.1 \%$ arabinose, $2.51 \pm 0.03 \%$ acetyl group, $24.2 \pm 0.6 \%$ klason lignin and $2.88 \pm 0.06 \%$ acid-soluble lignin. Standard compounds used for HPLC calibration, including glucose, xylose, arabinose, and cellubiose were purchased from Sigma Aldrich (Shanghai branch, Shanghai, China).The cellulase (Cellic $\left.{ }^{\circledR} \mathrm{CTec} 2\right)$ used for the hydrolysis of pretreated substrates was kindly provided by Novozymes (Beijing branch, Beijing, China), which was a multi-enzyme formulation with a determined cellulase activity (filter paper activity, FPA) of $114.07 \mathrm{FPU} / \mathrm{mL}$.

\subsection{Formic Acid Fractionation of Sugarcane Bagasse}

FA fractionation was carried out in a $500 \mathrm{~mL}$ three-neck glass flask heated by water bath or electric jacket under atmospheric pressure, with one of the necks connecting with a condenser. In this work, the liquid-to-solid ratio was selected as $15: 1(\mathrm{~L} / \mathrm{kg})$ in order to achieve a good system mixing. A total of $10 \mathrm{~g}$ of the screened bagasse was put into the three-neck glass flask, followed by the addition of $150 \mathrm{~mL} 60-90 \mathrm{wt} \%$ FA solution. Electrical stirring with a Teflon paddle was used at $300 \mathrm{rpm}$ to keep the system as homogeneous as possible. The reaction temperature was controlled at $80^{\circ} \mathrm{C}$ to the atmospheric boiling point of the aqueous FA solution $\left(\sim 107^{\circ} \mathrm{C}\right)$ by a water bath or electric-heating jacket. The reaction time of the fractionation was in the range $0.25-2.0 \mathrm{~h}$. After the reaction was finished, solids were recovered by suction filtration. The obtained solid was first washed with $150 \mathrm{~mL}$ $60-90 \mathrm{wt} \%$ FA solution to dissolve the residual lignin retained in the cellulosic solid and then filtered under pressure to remove as much liquid as possible. The solid was then rinsed with running water until neutrality. A portion of the washed solid was dried with acetone for chemical composition analysis, and the other part was stored at $4{ }^{\circ} \mathrm{C}$ for further enzymatic hydrolysis.

\subsection{Enzymatic Hydrolysis of Pretreated Sugarcane Bagasse}

The cellulosic solid obtained by FA fractionation were incubated at $50{ }^{\circ} \mathrm{C}, 150 \mathrm{rpm}$ in $50 \mathrm{mM}$ sodium acetate buffer ( $\mathrm{pH} 4.8)$ in an air-bath shaker. All experiments were 
performed in duplicate with $10 \mathrm{~mL}$ working volume at an initial solid consistency of $5 \%$ (g/mL) with cellulase loading of $15 \mathrm{FPU} / \mathrm{g}$ solid for $120 \mathrm{~h}$. Enzymatic digestibility was characterized by enzymatic glucan conversion (EGC, \%), defined as the percentage of glucan enzymatically converted to glucose.

\subsection{Analytical Methods}

The main chemical components of the used bagasse and pretreated solid were determined according to NREL's Laboratory Analytical Procedure [31]. The monosaccharide (glucose, xylose and arabinose) concentrations were determined by Shimadzu (Tokyo, Japan) HPLC (LC-10AT) system quipped with an Aminex HPX-87H column (BioRad, Hercules, CA, USA) and a differential refraction detector with $5 \mathrm{mM} \mathrm{H} 2 \mathrm{SO} 4$ as an eluent at a flow rate of $0.8 \mathrm{~mL} / \mathrm{min}$. The kinetic parameters were fitted by nonlinear fitting tools of Microsoft Excel 2010 software (Redmond, WA, USA).

\section{Conclusions}

An extended combined severity factor $\left(C S F_{\text {ext }}\right)$ was employed as an integrated parameter by involving the contribution of FA concentration, temperature and time to the reaction severity for modeling of the FA fractionation of sugarcane bagasse. Two phenomenological models based on the Arrhenius equation and modified Logistic equation were further used to describe the phenomenological kinetics, respectively. Different data-processing methods were compared to fit the severity parameters and model constants. It was found that using the data of solubilization of total xylan plus lignin fraction for fitting could obtain a good degree of fitting. Both Arrhenius-based and Logistic-based models showed a satisfying fitting accuracy for prediction of experimental data of xylan, lignin and xylan plus lignin solubilization, indicating that the linear models could generally be used to describe the phenomenological relationship between the solubilization of biomass components and CSF ext. Wide ranges of xylan solubilization (0.4-0.95), delignification (0.35-0.95) and total biomass solubilization (0.25-0.65) were observed, with an A-CSF ext range of 26-46 or L-CSF ext range of 37-47. Two distinct stages could be observed, as revealed by plots of CSF ext v.s. xylan and lignin solubilization with inflection points at A-CSF ext of 42 or L-CSF ext at 43 . For the enzymatic hydrolysis of cellulosic solids obtained by FA fractionation, the highest initial EGC (EGC@6h) was obtained at A-CSF ext of 39-40 or A-CSF ext of 40-41; however, for a relatively period of hydrolysis (EGC@6h), relatively high glucan conversion was observed at an A-CSF ext of 42-43 or A-CSF ext of 43-44. A higher $C S F_{\text {ext }}$ might result in a higher degree of cellulose formylation, especially with high FA concentration, which conversely decreased cellulose digestibility. However, post-alkaline saponification with a small amount of lime could recover the cellulose digestibility. CSF ext could be applied as an integrated parameter to evaluate the phenomenological kinetics of FA fractionation of sugarcane bagasse.

Author Contributions: Conceptualization, R.W. and X.Z.; methodology, J.Z. and X.Z.; validation, J.Z.; formal analysis, X.C.; investigation, X.C.; writing—original draft preparation, X.C.; writingreview and editing, R.W. and X.Z.; visualization, X.C. and X.Z; supervision, R.W. and X.Z.; project administration, R.W. and X.Z.; funding acquisition, J.Z., R.W. and X.Z. All authors have read and agreed to the published version of the manuscript.

Funding: This research was funded by National Natural Science Foundation of China, grant number 21808123, 21868008 and 21878176.

Institutional Review Board Statement: Not applicable.

Informed Consent Statement: Not applicable.

Data Availability Statement: Not applicable.

Conflicts of Interest: The authors declare no conflict of interest.

Sample Availability: Samples of the fractionated cellulosic pulps are available from the authors. 


\section{References}

1. Morikawa, Y.; Zhao, X.; Liu, D. Biological co-production of ethanol and biodiesel from wheat straw: A case of dilute acid pretreatment. RSC Adv. 2014, 4, 37878-37888. [CrossRef]

2. Ingle, A.P.; Chandel, A.K.; Antunes, F.A.F.; Mahendra, R.; da Silva, S.S. New trends in application of nanotechnology for the pretreatment of lignocellulosic biomass. Biofuels Bioprod. Biorefin. 2019, 13, 776-788. [CrossRef]

3. Levya, P.F.; Sandersona, J.E.; Kisperta, R.G.; Wise, D.L. Biorefining of biomass to liquid fuels and organic chemicals. Enzyme Microb. Technol. 1981, 3, 207-215. [CrossRef]

4. Zhao, X.; Zhang, L.; Liu, D. Biomass recalcitrance.Part I: The chemical compositions and physical structures affecting the enzymatic hydrolysis of lignocellulose. Biofuels Bioprod. Biorefin. 2012, 6, 465-482. [CrossRef]

5. Zhao, X.; Zhang, L.; Liu, D. Biomass recalcitrance. Part II: Fundamentals of different pre-treatments to increase the enzymatic digestibility of lignocellulose. Biofuels Bioprod. Biorefin. 2012, 6, 561-579. [CrossRef]

6. Himmel, M.E.; Ding, S.Y.; Johnson, D.K.; Adney, W.S.; Nimlos, M.R.; Brady, J.W.; Foust, T.D. Biomass recalcitrance: Engineering plants and enzymes for biofuels Production. Science 2007, 315, 804-807. [CrossRef]

7. Zhao, X.; Li, S.; Wu, R.; Liu, D. Organosolv fractionating pre-treatment of lignocellulosic biomass for efficient enzymatic saccharification: Chemistry, kinetics, and substrate structures. Biofuels Bioprod. Biorefin. 2017, 11, 567-590. [CrossRef]

8. Li, M.; Yang, S.; Sun, R. Recent advances in alcohol and organic acid fractionation of lignocellulosic biomass. Bioresour. Technol. 2016, 200, 971-980. [CrossRef] [PubMed]

9. Sindhu, R.; Binod, P.; Satyanagalakshmi, K.; Janu, K.U.; Sajna, K.V.; Kurien, N.; Sukumaran, R.K.; Pandey, A. Formic Acid as a Potential Pretreatment Agent for the Conversion of Sugarcane Bagasse to Bioethanol. Appl. Biochem. Biotechnol. 2010, 162, 2313-2323. [CrossRef] [PubMed]

10. Dussana, K.; Girisuta, B.; Haverty, D.; Leahy, J.J.; Hayes, M.H.B. The effect of hydrogen peroxide concentration and solid loading on the fractionation of biomass in formic acid. Carbohydr. Polym. 2014, 111, 374-384. [CrossRef]

11. Snelders, J.; Dornez, E.; Benjelloun-Mlayah, B.; Huijgen, W.J.J.; Wild, P.J.; Gosselink, R.J.A.; Gerritsma, J.; Courtin, C.M. Biorefining of wheat straw using an acetic and formic acid based organosolv fractionation process. Bioresour. Technol. 2014, 156, $275-282$. [CrossRef] [PubMed]

12. Xu, J.; Wang, L.; Zhi, Z.; Qiao, Y.; Zhao, C.; Lu, X. Enhancement of Acidogenic Fermentation of Corn Stover Hydrolysates by Thermal Pretreatment with Diluted Formic Acid as Catalyst. Energy Fuels 2015, 29, 8157-8161. [CrossRef]

13. Marzialetti, T.; Miller, S.J.; Jones, C.W.; Agrawal, P.K. Switchgrass pretreatment and hydrolysis using low concentrations of formic acid. J. Chem. Technol. Biot. 2011, 86, 706-713. [CrossRef]

14. Abatzoglou, N.; Chornet, E.; Belkacemi, K.; Overend, R.P. Phenomenological kinetics of complex systems-the development of a generalized severity parameter and its application to lignocellulosics fractionation. Chem. Eng. Sci. 1992, 47, 1109-1122. [CrossRef]

15. Overend, R.P.; Chornet, E. Fractionation of lignocellulosics by steam-aqueous pretreatemnts. Philos. Trans. R Soc. Lond. A 1987, 321, 523-536. Available online: https:/ / www.jstor.org/stable/37798 (accessed on 7 May 2021).

16. Chum, H.L.; Johnson, D.K.; Black, S.K.; Overend, R.P. Pretreatment catalyst effects and the combined severity parameter. Appl. Biochem. Biotechnol. 1990, 24, 1-14. [CrossRef]

17. Zhang, Z.; Vancov, T.; Mackintosh, S.; Basu, B.; Lali, A.; Qian, G.; Hobson, P.; Doherty, W.O.S. Assessing dilute acid pretreatment of different lignocellulosic biomasses for enhanced sugar production. Cellulose 2016, 23, 3771-3783. [CrossRef]

18. Gonzales, R.R.; Sivagurunathan, P.; Kim, S.H. Effect of severity on dilute acid pretreatment of lignocellulosic biomass and the following hydrogen fermentation. Int. J. Hydrogen Energy 2016, 41, 21678-21684. [CrossRef]

19. Iroba, K.L.; Tabil, L.G.; Sokhansanj, S.; Dumonceaux, T. Pretreatment and fractionation of barley straw using steam explosion at low severity factor. Biomass Bioenergy 2014, 66, 286-300. [CrossRef]

20. Zoulikha, M.R.; Thierry, M.; Qiuyu, Z.J.M.; Nouviaire, A.; Ahmed, R.S. Combined steamexplosion toward vacuum and dilute-acid spraying of wheat straw. Impact of severity factor on enzymatic hydrolysis. Renew. Energy 2015, 78, 516-526. [CrossRef]

21. Jang, S.; Kim, H.; Jeong, H.; Kim, J.; Yeo, H.; Choi, I.G. Effect of ethanol organosolv pretreatment factors on enzymatic digestibility and ethanol organosolv lignin structure from Liriodendron tulipifera in specifific combined severity factors. Renew. Energy 2016, 87, 599-606. [CrossRef]

22. Goh, C.S.; Tan, H.T.; Lee, K.T.; Brosse, N. Evaluation and optimization of organosolv pretreatment using combined severity factors and response surface methodology. Biomass Bioenergy 2011, 35, 4025-4033. [CrossRef]

23. Zhao, X.; Liu, D. Kinetic modeling and mechanisms of acid-catalyzed delignification of sugarcane bagasse by aqueous acetic acid. BioEnergy Res. 2013, 6, 436-447. [CrossRef]

24. Dong, L.; Wu, R.; Zhao, X.; Liu, D. Phenomenological modeling and evaluation of formic acid pretreatment of wheat straw with an extended combined severity factor for biomass fractionation and enzymatic saccharification to produce bioethanol. J. Taiwan Inst. Chem. Eng. 2017, 81, 140-149. [CrossRef]

25. Wu, R.; Zhao, X.; Liu, D. Structural features of formiline pretreated sugar cane bagasse and their impact on the enzymatic hydrolysis of cellulose. Sustain. Chem. Eng. 2016, 4, 1255-1261. [CrossRef]

26. Pan, X.; Gilkes, N.; Saddler, J. Effect of acetyl groups on enzymatic hydrolysis of cellulosic substrates. Holzforschung 2006, 60, 398-401. [CrossRef] 
27. Han, Y.; Bai, Y.; Zhang, J.; Liu, D.; Zhao, X. A comparison of different oxidative pretreatments on polysaccharide hydrolyzability and cell wall structure for interpreting the greatly improved enzymatic digestibility of sugarcane bagasse by delignification. $B I O B$ 2020, 7, 1-16. [CrossRef]

28. Brännvall, E. The Limits of delignifification in Kraft cooking. BioResources 2017, 12, 2081-2107. [CrossRef]

29. Chen, H.; Zhao, X.; Liu, D. Relative significance of the negative impacts of hemicelluloses on enzymatic cellulose hydrolysis is dependent on lignin content: Evidence from substrate structural features and protein adsorption. ACS Sustain. Chem. Eng. 2016, 4, 6668-6679. [CrossRef]

30. Zhao, X.; Liu, D. Multi-products co-production improves the economic feasibility of cellulosic ethanol: A case of Formiline pretreatment-based biorefining. Appl. Energy 2019, 250, 229-244. [CrossRef]

31. Sluiter, A.; Hames, B.; Ruiz, R.; Scarlata, C.; Sluiter, J.; Templeton, D.; Crocker, D.L.A.P. Determination of Structural Carbohydrates and Lignin in Biomass, Laboratory Analytical Procedure; Technical Report NREL/TP-510-42618; National Renewable Energy Laboratory: Golden, CO, USA, 2008; pp. 1-16. Available online: http:/ / www.nrel.gov/biomass/analyticalprocedures.html\#lap-002 (accessed on 7 May 2021). 